\title{
Produção e qualidade dos frutos da limeira ácida 'Tahiti' submetida a diferentes porcentagens de área molhada ${ }^{1}$
}

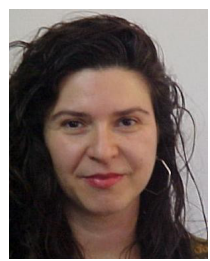

Maria J. H. de Souza², Márcio M. Ramos ${ }^{3}$, Dalmo L. de Siqueira ${ }^{4}$, Luiz C. Costa ${ }^{5}$, Arnaldo J. M. Lhamas ${ }^{6}$, Everardo C. Mantovani ${ }^{7}$, Paulo R. Cecon ${ }^{8} \&$ Luiz C. C. Salomão ${ }^{4}$

\footnotetext{
1 Parte da Tese de Doutorado do primeiro autor, financiada pelo CNPq

${ }^{2}$ DEA/UFV. CEP 36571-000, Viçosa, MG. Fone: (31) 3899-2734. E-mail: mjhatem@ufv.br (Foto)

3 DEA/UFV. Fone: (31) 3899-1914.E-mail: mmramos@ufv.br

${ }^{4}$ Departamento de Fitotecnia/UFV. Fone: (31) 3 899-1349. E-mails: siqueira@ufv.br e Isalomao@ufv.br

5 DEA/UFV. Fone: (31) 3899-2734. E-mail: I.costa@ufv.br

${ }^{6}$ Engenheiro Agrônomo. Fone: (31) 3892-6081. E-mail: penalhamas@bol.com.br

7 DEA/UFV. Fone: (31) 3899-1913. E-mail: everardo@ufv.br

8 Departamento de Informática/UFV. Fone: (31) 3899-1781. E-mail: cecon@dpi.ufv.br
}

Protocolo 162 - 6/11/2002 - Aprovado em 24/6/2003

\begin{abstract}
Resumo: Neste trabalho, avaliou-se a influência da porcentagem de área molhada (PW) sobre a produção de lima ácida 'Tahiti', no período de novembro de 2000 a novembro de 2001. O experimento foi conduzido com árvores de lima ácida 'Tahiti', em Visconde do Rio Branco, MG. Os tratamentos se constituíram de três porcentagens de área molhada $(15,31$ e 46\%), e de quatro períodos de estresse hídrico (sem estresse, estresse curto, médio e longo), além da testemunha (tratamento não-irrigado), totalizando $13(12+1)$ tratamentos. As diferentes porcentagens foram obtidas utilizando-se de três microaspersores com bocais e características diferentes. As características físico-químicas dos frutos, isto é, peso, diâmetro, comprimento, espessura da casca, porcentagem de suco e teor de sólidos solúveis (TSS) foram avaliadas no Laboratório de Análise de Frutas do Departamento de Fitotecnia da UFV. A porcentagem de área molhada não afetou significativamente a produção das árvores de lima ácida 'Tahiti'. A PW 15\% proporcionou frutos com TSS maior, seguida pela PW $31 \%$ e, por último, PW 46\%, sendo que esta diferença significativa não influenciou a qualidade do fruto.
\end{abstract}

Palavras-chave: Citrus latifolia Tanaka, porcentagem de área molhada, irrigação localizada

\section{Production and quality of the 'Tahiti' lime fruits submitted to different percentages of wetted area}

\begin{abstract}
This study aimed to evaluate the influence of the percentage of wetted area (PW) on the yield of the acid lime 'Tahiti' during the period of November 2000 to November 2001 in the municipality of Visconde do Rio Branco - MG. The treatments consisted of three percentages of wetted area $(15,31$ and $46 \%)$, and four periods of water stress (no stress, short stress, medium stress and long stress) and a control (nonirrigated treatment), totalizing 13 treatments. Different percentages of wetting were obtained by using three different microsprinklers. The physio-chemical characteristics of the fruits (weight, diameter, length, peel thickness, juice percentage and soluble solid contents) were evaluated at the Fruit Analysis Laboratory of the Phytotechnic Department of the Federal University of Viçosa. The yield of the 'Tahiti' acid lime was not significantly affected by the wetted area percentage. The $15 \mathrm{PW}$ provided fruits with higher soluble solid contents followed by 31 PW and finally by 46 PW, however, this significant difference, did not influences the quality of the fruit.
\end{abstract}

Key words: Citrus latifolia Tanaka, wetted area percentage, micro-sprinkler irrigation

\section{INTRODUÇÃO}

O uso e o manejo da irrigação podem influenciar o crescimento, o desenvolvimento e a qualidade final dos frutos cítricos, assim como a sua produção.

No Brasil, a irrigação em citricultura vem sendo utilizada desde meados de 1970, proporcionando bons resultados (Vieira,
1988). Mediante o suprimento adequado de água às plantas cítricas, a irrigação pode proporcionar os seguintes benefícios: maior pegamento de flores e frutos garantindo, também, maior produtividade; melhor qualidade dos frutos, com maior tamanho e peso, e coloração acentuada; maior quantidade de óleo na casca (Vieira 1991, citado por Pires, 1992), além de permitir, em determinadas condições, a colheita fora da época 
normal (Vieira, 1984). No Estado de São Paulo a produção anual de citros é de duas caixas por planta, $81,6 \mathrm{~kg}$ por árvore, enquanto naqueles irrigados a produção pode superar 12 caixas, 489,6 kg por árvore (Vieira, 1984).

Os sistemas de irrigação localizada têm sido utilizados na irrigação de fruteiras por proporcionarem uso mais eficiente da água e, dependendo das características dos emissores, eles proporcionam diferentes porcentagens de área molhada (PW).

$\mathrm{O}$ conhecimento sobre a porcentagem de área molhada e o perfil de molhamento do solo são necessários no dimensionamento e manejo da irrigação localizada, uma vez que afetam a produção da cultura e o crescimento, tanto do sistema radicular quanto da parte aérea da cultura. A porcentagem de área molhada e o perfil de molhamento do solo variam em função do tipo de solo, do tipo de emissor, do espaçamento entre emissores e da vazão do emissor (Vermeiren \& Jobling, 1980; Keller \& Karmeli, 1975, citado por Ramos et al., 1992), do tempo de aplicação de água e da lâmina de água aplicada (Bernardo,1995).

Bielorai (1982) estudou os efeitos da porcentagem de área molhada (PW) sobre a produção, eficiência do uso da água e qualidade do fruto, em pomelo irrigado por gotejamento e aspersão, em Negev, Israel. A maior produtividade (192,6 kg planta $^{-1}$ ) foi obtida nas plantas irrigadas com PW igual a $40 \%$, repondo-se $100 \%$ das necessidades hídricas das plantas. A quantidade de água aplicada afetou também a qualidade final dos frutos.

Em outro trabalho com pomelo irrigado, em Negev, o autor estudou o efeito de duas porcentagens de área molhada (30 e $50 \%$ ) na irrigação por gotejamento. A produção foi superior nas plantas dos tratamentos irrigados com PW de 50\%. O tamanho dos frutos também foi afetado pelos tratamentos, sendo que o irrigado com PW de $30 \%$ apresentou frutos menores (Bielorai, 1985).

Castel (1994) avaliou a resposta de árvores jovens de tangerina 'Clementina' (Citrus clementine, Hort. ex Tan) a diferentes tratamentos de irrigação por gotejamento, variando a quantidade de água aplicada $(50,80,110$ e $140 \%$ da evapotranspiração da cultura) e o número de emissores (dois e quatro por árvore). O trabalho foi conduzido no período de 1990 a 1992, em Moncada, Valência, Espanha. A produção das árvores não foi significativamente afetada pelo número de emissores mas pela quantidade de água aplicada. A maior produção foi obtida com uma aplicação de água correspondente a $140 \%$ da evapotranspiração da cultura (ETc). Para os tratamentos que receberam 50 e $80 \%$ da ETc, os frutos apresentaram casca mais espessa e maior teor de sólidos solúveis (TSS).

A literatura cita que, para cada tipo de cultura, existe um valor recomendado de PW. Para árvores e plantas cultivadas em parreiras, a PW varia de 33 a 67\%; por outro lado, se a irrigação for suplementar, a $\mathrm{PW}$ pode ter valor inferior a $33 \%$ em solos de textura média (Keller \& Bliesner, 1990). Bernardo (1995) comenta que, em regiões áridas, a PW deve ser de no mínimo $33 \%$, enquanto em regiões sujeitas a maiores precipitações, o seu valor mínimo pode ser de $20 \%$.

Esses valores podem ser alterados em função do regime de chuvas da região e da adaptabilidade do sistema radicular das culturas à redução do volume de solo utilizado na absorção de água e nutrientes.
Zekri \& Parsons (1989) trabalhando com pomelo irrigado, na Flórida, observaram que em climas áridos as raízes das árvores ficam confinadas em um pequeno volume de solo, adaptando-se bem ao pequeno volume molhado pelos emissores, porém em locais da Flórida, onde o clima é úmido e chuvoso, as raízes não ficam confinadas no volume molhado gerado pelos emissores. Em regiões chuvosas, uma PW pequena pode ser suficiente para árvores jovens, mas não para aquelas adultas.

Com o exposto, este trabalho objetivou avaliar a influência do uso da irrigação e da porcentagem de área molhada sobre a produção e qualidade do fruto da limeira ácida 'Tahiti'.

\section{MATERIAL E MÉTODOS}

O pomar onde foi conduzido este estudo está localizado na Estação Experimental da Sementeira, pertencente à Universidade Federal de Viçosa e localizada em Visconde do Rio Branco, MG ( $21^{\circ} 07^{\prime} \mathrm{S}, 42^{\circ} 27^{\prime} \mathrm{W}, 349 \mathrm{~m}$ de altitude). Os dados de temperatura e precipitação obtidos no local do experimento podem ser visualizados na Figura 1.

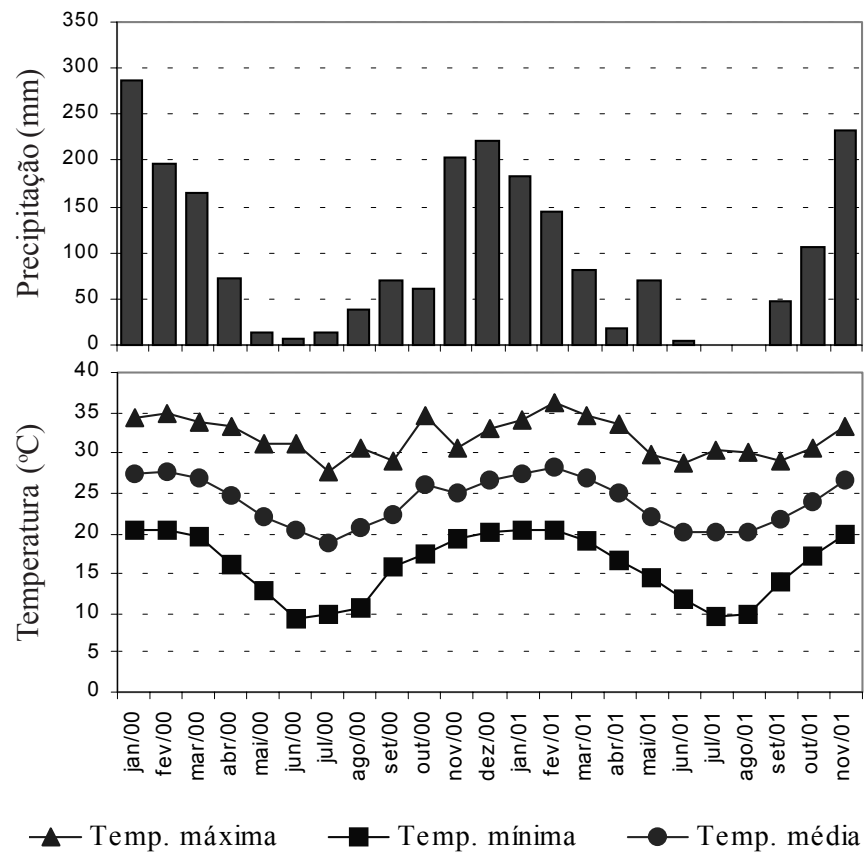

Figura 1. Dados de precipitação, temperaturas máxima, mínima e média no local do experimento, no período de janeiro de 2000 a novembro de 2001

As árvores de lima ácida 'Tahiti' (Citrus latifolia Tanaka) enxertadas no limão 'Cravo' (Citrus limonia Osbeck) foram plantadas em dezembro de 1996 no espaçamento 6 x $7 \mathrm{~m}$ em solo Latossolo Vermelho-Amarelo Distrófico. Para a camada de 0 a $20 \mathrm{~cm}$ de profundidade a textura é argilo-arenosa, sendo a densidade aparente (Da) de $1,4 \mathrm{~g} \mathrm{~cm}^{-3}$, a capacidade de campo (CC) de $23,4 \%$ e o ponto de murcha (PM) de $16,3 \%$ e, para a camada de 20 a $40 \mathrm{~cm}$, a textura é argilosa, a Da de $1,32 \mathrm{~g} \mathrm{~cm}^{-3}$, a CC de $28,6 \%$ e o PM de 20,1\% (tanto na CC quanto no PM, a porcentagem é em peso e corresponde, respectivamente, à tensão de 0,3 bar e 15 bar). 
$\mathrm{O}$ experimento foi conduzido em parcelas subdivididas tendo, nas parcelas, três porcentagens de área molhada e, nas subparcelas, quatro períodos de estresse hídrico, num delineamento em blocos casualizados com três repetições. Os tratamentos consistiram de três porcentagens de área molhada $(15,31 \mathrm{e}$ $46 \%$ e quatro períodos de estresse hídrico, ou seja, sem estresse (SE), estresse curto (EC), estresse médio (EM) e estresse longo (EL) proporcionados por quatro períodos sem irrigação $(0,7$, 10 e 13 semanas, durante os meses de junho a agosto de 2000 e de maio a julho de 2001), e a testemunha, tratamento nãoirrigado, totalizando $13(12+1)$ tratamentos. Cada parcela foi constituída por oito plantas, as subparcelas por duas e cada bloco por $26(24+2)$ totalizando 78 plantas, conforme a Figura 2. A disposição dos três blocos no campo foi feita do seguinte modo: o bloco 1, na parte superior da área; o bloco 2, na parte intermediária e o bloco 3, na parte inferior, à direita.

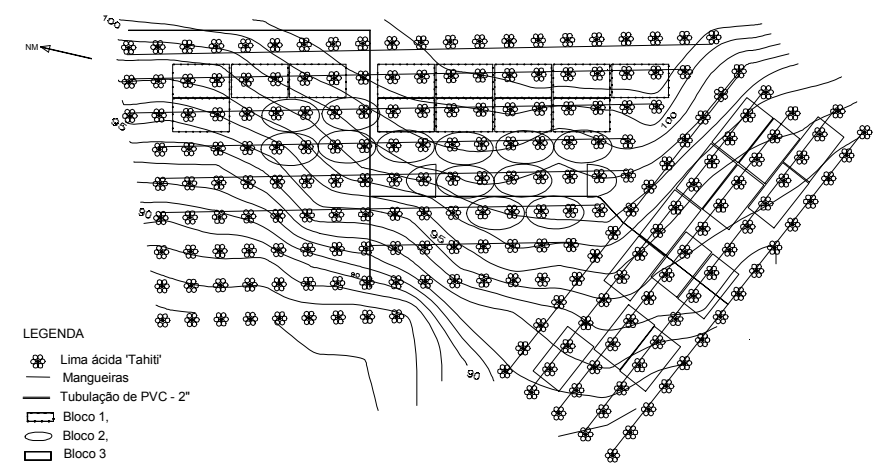

Figura 2. Croqui da área experimental, do sistema de irrigação e das plantas utilizadas no experimento

Utilizou-se de um sistema de irrigação por microaspersão, sendo que as três porcentagens de área molhada foram obtidas mediante três microaspersores com bocais e características diferentes, conforme apresentado na Tabela 1. Os microaspersores foram instalados a $1 \mathrm{~m}$ de distância do tronco da planta, no sentido da fileira. Para garantir boa uniformidade de aplicação de água, os microaspersores foram regulados individualmente, de modo a trabalharem à pressão de serviço de 10 mca.

Tabela 1. Características dos microaspersores utilizados na irrigação das árvores

\begin{tabular}{ccccccc}
\hline $\begin{array}{c}\text { Cor do } \\
\text { Bocal }\end{array}$ & Difusor & $\begin{array}{c}\mathrm{Db} \\
\mathrm{mm}\end{array}$ & $\begin{array}{c}\mathrm{Ps} \\
\mathrm{mca}\end{array}$ & $\begin{array}{c}\mathrm{V} \\
\mathrm{L} \mathrm{h}^{-1}\end{array}$ & $\begin{array}{c}\mathrm{Dc} \\
\mathrm{m}\end{array}$ & $\begin{array}{c}\mathrm{PW} \\
\%\end{array}$ \\
\hline Roxo & Pequeno & 1,0 & 10 & 37 & 2,0 & 15 \\
Branco & Pequeno & 2,0 & 10 & 138 & 2,9 & 31 \\
Verde & Longo alcance & 1,8 & 10 & 116 & 3,5 & 46 \\
\hline $\begin{array}{l}\text { Db, diâmetro do bocal; Ps, pressão de serviço; } \\
\text { porcentagem de área molhada; }\end{array}$ & \multicolumn{5}{c}{ Dc, diâmetro de cobertura; PW, } \\
\end{tabular}

O manejo da irrigação baseou-se em dados coletados em um tanque Classe " $\mathrm{A}$ " e em um pluviômetro, instalados na estação experimental. Para se determinar a evapotranspiração da cultura de referência (ETo) foi utilizado o coeficiente do tanque $(\mathrm{Kt})$, sendo este definido em função da umidade relativa do ar, da velocidade do vento e das características de instalação do tanque (circundado com grama) com valor médio igual a 0,75 (Bernardo, 1995). O coeficiente de cultivo para o cálculo da evapotranspiração da cultura (ETc) foi definido com base nos valores apresentados por Doorenbos \& Pruitt (1977), considerando-se árvores com cobertura vegetal inferior a $20 \%$, e cultivo isento de ervas daninhas, acrescido em $10 \%$, valor este recomendado para os limões, obtendo-se um Kc médio de 0,55.

A porcentagem de área molhada considerada para o cálculo da evapotranspiração da cultura na irrigação localizada (ETcg) foi $31 \%$, de forma que todas as árvores receberam o mesmo volume de água e a freqüência de irrigação foi de duas aplicações por semana.

O cálculo da lâmina aplicada foi feito de acordo com metodologia apresentada por Bernardo (1995):

$$
\begin{gathered}
\mathrm{ETo}=\mathrm{EV} \mathrm{Kt} \\
\mathrm{ETc}=\mathrm{ETo} \mathrm{Kc} \\
\mathrm{ETcg}=\mathrm{ETc}(31 / 100) \\
\mathrm{IRN}=\mathrm{ETcg} \\
\mathrm{ITN}=(\mathrm{IRN} / \mathrm{Ea})
\end{gathered}
$$

em que ETo é a evapotranspiração de referência, mm; EV, a evaporação do tanque, $\mathrm{mm}$; Kt, o coeficiente do tanque; ETc, a evapotranspiração da cultura, mm; Kc, o coeficiente de cultivo para a lima ácida 'Tahiti'; ETcg, a evapotranspiração da cultura de lima ácida, mm, sob irrigação localizada, considerando-se uma porcentagem de área molhada de $31 \%$; IRN, a irrigação real necessária, mm; ITN, a irrigação total necessária, mm; e Ea, a eficiência de aplicação (centesimal), considerada $90 \%$.

Avaliou-se a produção de lima ácida 'Tahiti' durante os meses de novembro de 2000 a novembro de 2001, cujos dados foram analisados por meio de análise de variância segundo metodologia apresentada por David \& Kronka (1989). Uma análise foi feita para os 13 tratamentos (incluindo-se a testemunha), em um delineamento em blocos casualizados, e a outra para os 12 tratamentos irrigados, em um delineamento, também em blocos casualizados, mais em parcelas subdivididas.

Como a interação entre os fatores porcentagem de área molhada e períodos de estresse não foi significativa e também por ter observado diferença significativa entre alguns tratamentos sempre irrigados e a testemunha optou-se, neste trabalho, por apresentar e discutir os resultados obtidos nas três porcentagens de área molhada, bem como dos tratamentos sempre irrigados e a testemunha.

Os resultados obtidos nas três porcentagens de área molhada foram calculados como a média dos valores dos quatro tratamentos de estresse e comparados pelo teste de Tukey (p $<0,05)$. Para a comparação da testemunha com os três tratamentos sempre irrigados, utilizou-se o teste de Dunnet $(\mathrm{p}<$ 0,05), conforme metodologia apresentada por David \& Kronka (1989).

Para se identificar as características comerciais dos frutos, nos diferentes tratamentos, amostraram-se, aleatoriamente, dez frutos de cada árvore, nos meses de novembro e dezembro de 2000. O diâmetro equatorial, o comprimento, a espessura de 
casca e o peso do fruto, foram determinados através da metodologia apresentada por Coelho \& Cunha (1982), enquanto a porcentagem de suco e o teor de sólidos solúveis foram determinados de acordo com os procedimentos apresentados por Carvalho \& Nogueira (1979). Essas determinações foram feitas no Laboratório de Análise de Frutas do Departamento de Fitotecnia da UFV.

Os procedimentos estatísticos foram os mesmos aplicados para os dados de produção, como descrito anteriormente.

\section{RESULTADOS E DISCUSSÃO}

$\mathrm{Na}$ Tabela 2 são apresentados os valores de produção obtidos nas três porcentagens de área molhada (15, 31 e 46\%), média dos quatro tratamentos de estresse, no período de novembro de 2000 a novembro de 2001. Observa-se, nesta tabela, não ter havido efeito significativo das três porcentagens de área molhada, em nível de $5 \%$ de probabilidade, pelo teste de Tukey, em nenhum dos meses avaliados.

Apesar de não ocorrer diferença significativa em nível de $5 \%$, observa-se que o maior valor absoluto para produção (Tabela 2) ocorreu na porcentagem de $46 \%$ em, praticamente, todo o período estudado. A produção total obtida na PW 46\% foi de 93,3 kg por árvore, enquanto na PW 15\% de 76,5. Tal ocorrência é devida, provavelmente, ao fato das árvores deste tratamento (PW 46\%) terem aproveitado melhor a água de irrigação, por esta se concentrar mais na superfície, ao contrário da PW 15\% em que a água da irrigação se aprofunda mais no solo molhando menor área superficialmente. Resultado semelhante foi encontrado por Bielorai (1985), em que a produção de pomelo, sob sistema de irrigação localizada, foi superior no tratamento irrigado por duas laterais (PW 50\%), quando comparado com o de uma lateral (PW 30\%) obtendose, em 1976, uma produção de 104,4 e 126 kg por árvore e em 1977 de 117 e 133,2 kg por árvore, para os tratamentos irrigados com uma e duas laterais, respectivamente. Segundo o autor, a concentração de raízes foi ligeiramente superior no tratamento irrigado com duas laterais.

Os valores de peso médio de frutos obtidos nas três porcentagens de área molhada são apresentados na Tabela 3. Não houve diferença significativa, ao nível de 5\% pelo teste Tukey, para nenhuma das três porcentagens.

$\mathrm{Na}$ Tabela 4 são apresentados os valores das características comerciais dos frutos. Entre as três porcentagens de área molhada, a PW de $15 \%$ proporcionou frutos com TSS maior, seguindo-se a PW de $31 \%$ e, por último, a PW de $46 \%$, sendo que esta diferença significativa não diferencia a qualidade do fruto, uma vez que, dentro dos padrões comerciais de frutos tipo B (frutos tipo exportação, segundo Gayet et al., 1995), o TSS deve estar entre 7 e $8^{\circ}$ Brix.

Na Figura 3 estão os dados de produção de lima ácida, em $\mathrm{kg}$ por árvore, obtidos nas três porcentagens de área molhada, para o tratamento sem estresse hídrico (SE) e para a testemunha, nos meses de novembro de 2000 a novembro de 2001, enquanto a Figura 4 contém dados da produção total obtida neste período.

O tratamento irrigado SE PW de $46 \%$ proporcionou a maior produção total, ou seja, 109,6 kg por árvore, quando comparado, a nível de $5 \%$ pelo teste de Dunnett, com a testemunha $(58,1 \mathrm{~kg}$ por árvore). Este fato vem ao encontro dos resultados apresentados por Vieira (1984) segundo os quais a aplicação de irrigação pode aumentar a produção anual das árvores de citros.

Nos meses de junho, julho e novembro de 2001, o tratamento irrigado SE PW de 46\% também diferiu do

Tabela 2. Produção média por árvore, em kg, de lima ácida 'Tahiti', para as três porcentagens de área molhada, média dos quatro períodos de estresse

\begin{tabular}{|c|c|c|c|c|c|c|c|c|c|c|c|c|c|c|}
\hline \multirow{2}{*}{ Tratamentos } & \multicolumn{2}{|c|}{2000} & \multicolumn{11}{|c|}{2001} & \multirow{2}{*}{ Total } \\
\hline & Nov & Dez & Jan & Fev & Mar & Abr & Mai & Jun & Jul & Ago & Set & Out & Nov & \\
\hline PW 15\% & $3,4 \mathrm{a}$ & $4,6 \mathrm{a}$ & $10,4 \mathrm{a}$ & $4,3 \mathrm{a}$ & $6,5 \mathrm{a}$ & $8,3 \mathrm{a}$ & $4,2 \mathrm{a}$ & $11,7 \mathrm{a}$ & $5,8 \mathrm{a}$ & $8,1 \mathrm{a}$ & $3,1 \mathrm{a}$ & $2,0 \mathrm{a}$ & $8,3 \mathrm{a}$ & $80,6 \mathrm{a}$ \\
\hline PW 31\% & $3,3 \mathrm{a}$ & $4,4 \mathrm{a}$ & $9,4 \mathrm{a}$ & $4,2 \mathrm{a}$ & $7,4 \mathrm{a}$ & $10,3 \mathrm{a}$ & $4,1 \mathrm{a}$ & $8,2 \mathrm{a}$ & $6,0 \mathrm{a}$ & $7,5 \mathrm{a}$ & $3,6 \mathrm{a}$ & $1,3 \mathrm{a}$ & $6,7 \mathrm{a}$ & $76,5 \mathrm{a}$ \\
\hline
\end{tabular}

" PW é a porcentagem de área molhada. As médias seguidas de mesma letra, na mesma coluna, não diferem entre si ao nível de 5\%, pelo teste de Tukey

Tabela 3. Peso médio de frutos ${ }^{1}$, em grama, para as três porcentagens de área molhada

\begin{tabular}{|c|c|c|c|c|c|c|c|c|c|c|c|c|c|c|}
\hline \multirow{2}{*}{ Tratamentos $^{*}$} & \multicolumn{2}{|c|}{2000} & \multicolumn{11}{|c|}{2001} & \multirow{2}{*}{ Total } \\
\hline & Nov & Dez & Jan & Fev & Mar & $\mathrm{Abr}$ & Mai & Jun & Jul & Ago & Set & Out & Nov & \\
\hline PW 15\% & $80 a$ & $68 \mathrm{a}$ & $75 a$ & $75 \mathrm{a}$ & $72 a$ & $76 a$ & $80 a$ & $81 \mathrm{a}$ & $72 a$ & $68 a$ & $72 a$ & $82 \mathrm{a}$ & $73 a$ & $75 \mathrm{a}$ \\
\hline PW 31\% & $79 \mathrm{a}$ & $70 \mathrm{a}$ & $74 \mathrm{a}$ & $76 \mathrm{a}$ & $71 \mathrm{a}$ & $76 \mathrm{a}$ & $81 \mathrm{a}$ & $79 \mathrm{a}$ & $69 \mathrm{a}$ & $64 \mathrm{a}$ & $67 \mathrm{a}$ & $75 \mathrm{a}$ & $73 \mathrm{a}$ & $73 \mathrm{a}$ \\
\hline PW 46\% & $79 a$ & $68 \mathrm{a}$ & $74 \mathrm{a}$ & $72 \mathrm{a}$ & $72 \mathrm{a}$ & $75 \mathrm{a}$ & $78 \mathrm{a}$ & $77 \mathrm{a}$ & $73 \mathrm{a}$ & $66 \mathrm{a}$ & $72 \mathrm{a}$ & $76 \mathrm{a}$ & $72 \mathrm{a}$ & $73 \mathrm{a}$ \\
\hline
\end{tabular}

As médias seguidas pela mesma letra, em uma mesma coluna, não diferem ao nível de $5 \%$, pelo teste de Tukey

PW - porcentagem de área molhada

Tabela 4. Características físico-químicas ${ }^{1}$ dos frutos de lima ácida 'Tahiti' para as três porcentagens de área molhada

\begin{tabular}{|c|c|c|c|c|c|c|c|}
\hline \multirow{2}{*}{ Tratamentos ${ }^{*}$} & $\mathrm{D}$ & $\mathrm{C}$ & \multirow{2}{*}{$\mathrm{D} / \mathrm{C}$} & \multirow{2}{*}{$\begin{array}{l}\mathrm{Ec} \\
\mathrm{cm}\end{array}$} & \multirow{2}{*}{$\begin{array}{l}\text { TSS } \\
{ }^{\circ} \text { brix }\end{array}$} & \multirow{2}{*}{$\begin{array}{l}\text { Teor de } \\
\text { Suco } \%\end{array}$} & \multirow{2}{*}{$\begin{array}{c}\text { Peso } \\
\mathrm{g}\end{array}$} \\
\hline & \multicolumn{2}{|c|}{$\mathrm{mm}$} & & & & & \\
\hline PW 15\% & $52,02 \mathrm{a}$ & $59,43 \mathrm{a}$ & $1,14 \mathrm{a}$ & $3,21 \mathrm{a}$ & $7,55 \mathrm{a}$ & $43,42 \mathrm{a}$ & $80,91 \mathrm{a}$ \\
\hline PW 31\% & $51,82 \mathrm{a}$ & 59,44 a & $1,15 \mathrm{a}$ & $3,21 \mathrm{a}$ & $7,36 \mathrm{ab}$ & $45,89 \mathrm{a}$ & $81,00 \mathrm{a}$ \\
\hline PW 46\% & $52,05 \mathrm{a}$ & $59,30 \mathrm{a}$ & $1,14 \mathrm{a}$ & $3,29 \mathrm{a}$ & $7,33 \mathrm{~b}$ & $43,40 \mathrm{a}$ & $82,05 \mathrm{a}$ \\
\hline
\end{tabular}

${ }^{1}$ As médias seguidas pela mesma letra, em uma mesma coluna, não diferem ao nível de $5 \%$, pelo teste de Tukey

TSS - teor de sólidos solúveis; D - Diâmetro dos frutos; C - Comprimento dos frutos; PW - porcentagem de área molhada 


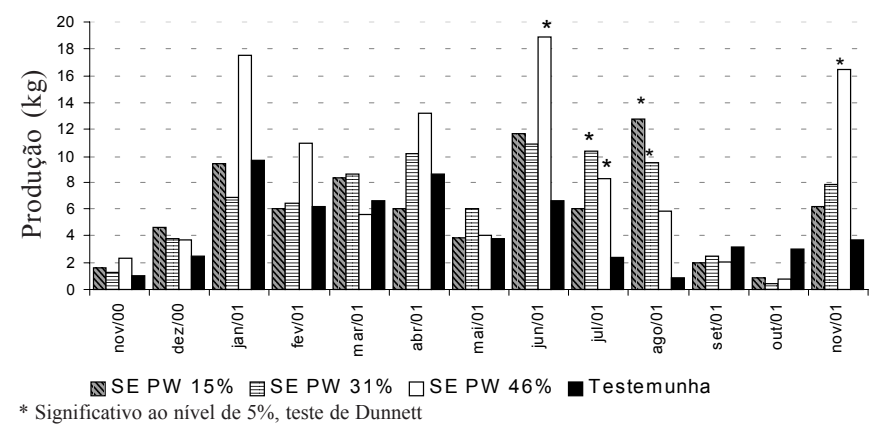

Figura 3. Produção de lima ácida 'Tahiti', em kg, nas três porcentagens de área molhada, para o tratamento SE e para a testemunha, no período de novembro de 2000 a novembro de 2001

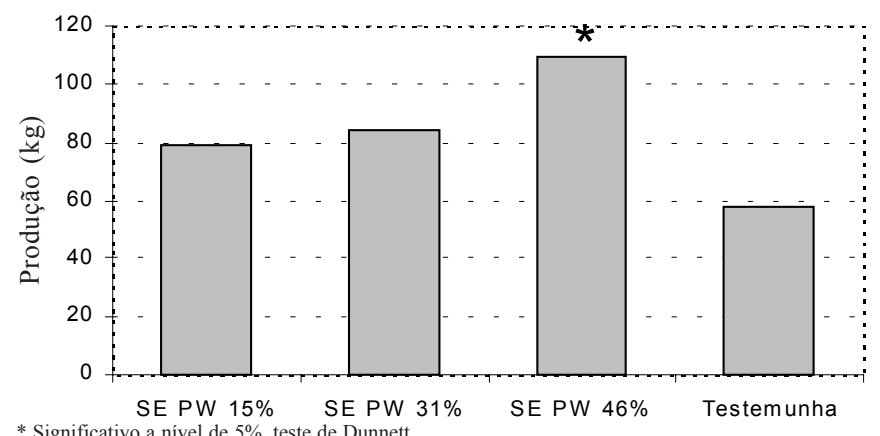

Figura 4. Produção total de lima ácida 'Tahiti', em kg, no período de novembro de 2000 a novembro de 2001 , nas três porcentagens de área molhada, para o tratamento SE e para a testemunha

não-irrigado, com uma produção maior; já no mês de agosto de 2001 os tratamentos irrigados SE PW 31\% e SE PW $15 \%$, também diferiram da testemunha. A produção obtida em novembro de 2001 foi proveniente de flores que abriram em junho de 2001 mês em que a indução floral ocorreu em razão, provavelmente, do período de repouso ocasionado pelas baixas temperaturas, conforme apresentado na Figura 1.

As produções obtidas nos meses de junho, julho e agosto de 2001, resultaram de flores abertas em fevereiro e março de
2001. De janeiro a março, meses de elevada evapotranspiração e de ocorrência de grandes períodos sem chuva, foram verificados problemas na condução da irrigação devido a entupimentos dos filtros, ocasionados pela elevada turbidez da água captada para a irrigação, levando a uma redução na pressão e na vazão dos microaspersores, resultando em uma lâmina menor de irrigação aplicada e ocasionando, um período de estresse hídrico nesses meses, que possivelmente influenciou a floração de fevereiro e março de 2001.

$\mathrm{Na}$ Tabela 5 têm-se os valores de peso médio de frutos obtidos nos tratamentos sem estresse, para as três porcentagens de área molhada.

O tratamento irrigado SE PW 46\% resultou em frutos com maior peso médio, diferindo da testemunha no mês de novembro de 2000 e durante o período de agosto a novembro de 2001. Nos meses de maio, outubro e novembro, os tratamentos SE PW 15\% e SE PW 31\% diferiram da testemunha, apresentando frutos com peso médio maior; já em setembro de 2001, apenas o tratamento SE PW 46\% diferiu da testemunha.

As produções de agosto e de setembro de 2001 foram provenientes de flores, que iniciaram a abertura em março e abril de 2001 (Souza, 2001). Em outubro e novembro de 2001, todos os tratamentos irrigados diferiram da testemunha. A produção de novembro de 2001 foi proveniente de flores que se abriram em junho de 2001 (Souza, 2001), sendo que, no período de junho a novembro de 2001, as árvores pertencentes ao tratamento não-irrigado (testemunha) dispu-seram de menor quantidade de água para seu desenvolvimento e crescimento dos frutos, reforçando o comentário de que a aplicação de irrigação pode proporcionar frutos com maior peso médio, além de concordar com os comentários de Doorenbos \& Kassam (1979) de que os déficits hídricos podem afetar o tamanho final dos frutos. O aumento do tamanho do fruto até a colheita depende muito da absorção de água.

As características físico-químicas dos frutos da lima ácida 'Tahiti' obtidos nas três porcentagens de área molhada, para o tratamento sem estresse, são apresentadas na Tabela 6. A

Tabela 5. Peso médio de frutos de lima ácida 'Tahiti', em grama, para as três porcentagens de área molhada no tratamento sem estresse, para o período de novembro de 2000 a novembro de 2001

\begin{tabular}{|c|c|c|c|c|c|c|c|c|c|c|c|c|c|c|}
\hline \multirow{2}{*}{ Tratamentos } & \multicolumn{2}{|c|}{2000} & \multicolumn{11}{|c|}{2001} & \multirow{2}{*}{ Média } \\
\hline & Nov & Dez & Jan & Fev & Mar & Abr & Mai & Jun & Jul & Ago & Set & Out & Nov & \\
\hline SE PW 15\% & 80,2 & 66,6 & 75,7 & 71,7 & 72,7 & 77,3 & $82,1^{*}$ & 79,6 & 66,5 & 61,7 & 73,0 & $90,8^{*}$ & $72,8^{*}$ & 73,2 \\
\hline SE PW 31\% & 81,7 & 72,8 & 72,1 & 77,7 & 71,4 & 74,1 & $84,3 *$ & 78,3 & 68,5 & $68,3 *$ & 73,2 & $84,0 *$ & $73,9 *$ & 75,4 \\
\hline SE PW 46\% & $85,0^{*}$ & 67,3 & 75,6 & 71,5 & 74,1 & 78,6 & 77,9 & 78,5 & 72,0 & $72,7^{*}$ & $78,8^{*}$ & $84,6^{*}$ & $77,6^{*}$ & $76,5^{*}$ \\
\hline Testemunha & 72,3 & 71,2 & 70,4 & 77,0 & 70,1 & 71,8 & 72,2 & 71,0 & 65,2 & 55,4 & 60,2 & 65,3 & 63,7 & 69,3 \\
\hline
\end{tabular}

- porcentagem de área molhada; SE, sem estresse

Tabela 6. Características físico-químicas dos frutos de lima ácida ‘Tahiti', para as três porcentagens de área molhada, média para o tratamento sem estresse

\begin{tabular}{|c|c|c|c|c|c|c|c|}
\hline \multirow{2}{*}{ Tratamentos } & $\mathrm{D}$ & $\mathrm{C}$ & \multirow{2}{*}{$\mathrm{D} / \mathrm{C}$} & \multirow{2}{*}{$\begin{array}{l}\mathrm{Ec} \\
\mathrm{cm}\end{array}$} & \multirow{2}{*}{$\begin{array}{l}\text { TSS } \\
{ }^{\circ} \text { brix }\end{array}$} & \multirow{2}{*}{$\begin{array}{c}\text { Teor Suco } \\
\%\end{array}$} & \multirow{2}{*}{$\begin{array}{c}\text { Peso } \\
\mathrm{g}\end{array}$} \\
\hline & \multicolumn{2}{|c|}{$\mathrm{mm}$} & & & & & \\
\hline SE PW $15 \%$ & 51,66 & 57,79 & 1,119 & 3,13 & 7,63 & 42,73 & 78,1 \\
\hline SE PW $31 \%$ & $52,50 *$ & 59,42 & 1,132 & $3,36^{*}$ & 7,34 & 45,81 & $83,6^{*}$ \\
\hline Testemunha & 50,22 & 57,77 & 1,150 & 3,02 & 7,87 & 47,99 & 72,9 \\
\hline
\end{tabular}

PW - porcentagem de área molhada; TSS - teor de sólidos solúveis; D - diâmetro dos frutos; C - comprimento dos frutos; Ec - espessura de casca

* Significativo ao nível de $5 \%$, teste de Dunnett 
testemunha produziu frutos com menor peso médio, menor espessura de casca e menor diâmetro, diferindo dos tratamentos SE PW 31\% e SE PW 46\%, enquanto para as demais características não foram verificadas diferenças significativas pelo teste de Dunnett.

\section{CONCLUSÕES}

1. A porcentagem de área molhada não afetou significativamente a produção das árvores de lima ácida 'Tahiti'.

2. A qualidade final dos frutos não foi afetada pelas diferentes porcentagens de área molhada.

3. O uso da irrigação afetou a produção total, sendo que o maior valor absoluto (109,6 $\mathrm{kg}$ por árvore) foi obtido com a maior porcentagem de área molhada.

4. A irrigação proporcionou aumento do tamanho final dos frutos.

\section{AGRADECIMENTOS}

O primeiro autor agradece ao CNPq, pelo apoio financeiro. Aos Departamentos de Engenharia Agrícola e de Fitotecnia, pelo apoio técnico. Aos funcionários da garagem central da UFV e da Estação Experimental da Sementeira, pelo apoio durante a execução prática deste trabalho. Aos estagiários e a todos aqueles que colaboraram para a realização deste trabalho.

\section{LITERATURA CITADA}

Bernardo, S. Manual de Irrigação. Viçosa, MG: UFV, Imprensa Universitária., 1995. 657p.

Bielorai, $\mathrm{H}$. The effect of partial wetting on the root zone on yield and water use efficiency in a drip and splinkler-irrigated mature grapefruit grove. Irrigation Science, Berlin, v.3, n.2, p.89-100, 1982.

Bielorai, H. Moisture, salinity and root distribution of drip irrigated grapefruit. Proceedings of the Third International Drip/Trickle Irrigation Congress, Fresno, v.2, p.562-567, 1985.

Carvalho, V.D.; Nogueira, D.J.P. Qualidade, maturação e colheita dos citros. Informe Agropecuário, Belo Horizonte, MG. v.5, n. 52, p.61-67, 1979.

Castel, J.R. Response of young Clementine citrus trees to drip irrigation. I. Irrigation amount and number of drippers. Journal of Horticultural Science, Ashford, v.3, n.69, p.481489, 1994.
Coelho, Y.S; Cunha, G.A.P. Critérios de avaliação da maturação e qualidade de frutos, com ênfase para citros e abacaxi. Cruz das Almas, BA: EMBRAPA-CNPMF, 1982. 20p. Circular Técnica, CNPMF, 1

David, A.B.; Kronka, S.N. Experimentação Agrícola. Jaboticabal: FUNEP, 1989. 247p.

Doorenbos, J.; Kassam, A.H. Yield response to water. Rome: FAO, 1979. 306p. Irrigation and Drainage, Paper 33

Doorenbos, J.; Pruitt, W.O. Crop water requirement. Rome: FAO, 1977. 144p. Irrigation and Drainage, 24

Gayet, J.P.; Bleinroth, E.W.; Matallo, M.; Garcia, E.E.C.; Garcia, A.E.; Ardito, E.F.G.; Bordin, M.R.; Lima ácida 'Tahiti' para a exportação: Procedimentos de colheita e pós-colheita. Brasília: EMBRAPA - SPI, 1995. 36p. Série Publicações Técnicas FRUPEX, 12

Keller, J.; Bliesner, R.D. Sprinker and trickle irrigation. New York: An Avi Book, 1990, 652p.

Marsh, A.W. Irrigation. In: Renther, W. (ed) The citrus industry. Riverside: University of California, v.3, n.8, 1973, p.230-279.

Pires, R.C.M., Manejo da água na irrigação dos citros. Laranja. Cordeirópolis, v.13, n.1, p.237-260, 1992.

Ramos, M.M.; Salles, E.S.; Couto, L.; Bernardo, S. Efeito da vazão e do volume de água aplicados por um emissor pontual em latossolo vermelho-escuro álico, nas dimensões do bulbo molhado. Engenharia na Agricultura, Viçosa - Série Irrigação e Drenagem, v.1, n.7, 16p, 1992.

Roth, R.L.; Sanchez, C.A.; Gardner, B.R. Valencias under pressurized irrigation. Citrograph, Los Angeles, v.80, n.12, p.7-18, 1995.

Souza, M.J.H. Análises do manejo de água, graus-dia, radiação interceptada e produtividade na lima ácida 'Tahiti'. Viçosa: Universidade Federal de Viçosa, MG, 2001. 94p. Tese Doutorado

Vermeiren, L.; Jobling, G.A. Irrigação localizada. Roma: FAO, 1980. 184p. Irrigação e Drenagem, 36

Vieira, D.B. Controle da irrigação em citricultura. Laranja, Cordeirópolis, v.1, n.5, p.299-312. 1984.

Vieira, D.B. Produtividade e irrigação. In: Simpósio de Citricultura. Produtividade dos Citros, 3, 1988, Jaboticabal. Anais... Jaboticabal: FUNEP, 1988. p.185-193.

Zekri, M.; Parsons, L.R. Grapefruit leaf and fruit growth in response to drip, microsprinkler, and overhead sprinkler irrigation. Journal of American Society for Horticultural Science, St. Joseph, v.1, n.114, p.25-29, 1989. 